\title{
Modelling turn away intention of information technology professionals in Bangladesh: a partial least squares approach
}

\author{
Md. Shohel Arman', Rozina Akter' ${ }^{2}$ Imran Mahmud ${ }^{3}$, T. Ramayah \\ ${ }^{1}$ Department of Software Engineering, Daffodil International University, Bangladesh \\ ${ }^{2}$ Department of Business Administration, Daffodil International University, Bangladesh \\ ${ }^{3}$ Department of Information Technology and Management, Daffodil International University, Bangladesh \\ ${ }^{4}$ School of Management, Universiti Sains Malaysia, Malaysia
}

\begin{tabular}{l} 
Article Info \\
\hline Article history: \\
Received Jun 6, 2019 \\
Revised Mar 9, 2020 \\
Accepted Mar 21, 2020 \\
\hline Keywords: \\
Bangladesh \\
Information technology (IT) \\
IT professionals \\
Software companies \\
Threat of professional \\
obsolescence \\
Turn-away intentions
\end{tabular}

Article Info

Article history:

Received Jun 6, 2019

Revised Mar 9, 2020

Accepted Mar 21, 2020

\section{words}

Bangladesh

IT professionals

Software companies

obsolescence

\begin{abstract}
Despite, Bangladesh produces many IT graduates each year but only one tenth of total graduates contribute in IT development sector. In order to keep the contribution to economy through IT development, it is crucial for IT industry to know the factors that influence turn away of IT graduates. In this paper, building upon role stress theory, we develop a research model to explore the influence of workplace exhaustion and threat of professional obsolescence (TPO). Data were gathered from 185 IT professionals from 15 different IT companies through survey questionnaire. The structural equation modelling technique was used to test the paths. The results suggests that strong influence of TPO on turn-away intentions. Result also suggests significant roles of work overload, family-career conflict and control over career and workplace exhaustion on turn away intention. This paper contributes to the body of work dedicated to helping us better understand the turn away behaviour from the workplace exhaustion and TPO perspectives. From the viewpoint of practice, this research sheds light on some of the challenges that the IT industry might face when making strategy and policy to control turn away from IT profession in Bangladesh.
\end{abstract}

Copyright (c) 2020 Institute of Advanced Engineering and Science. All rights reserved.

\section{Corresponding Author:}

Imran Mahmud,

Department of Information Technology and Management,

Daffodil International University,

Mirpur Rd, Dhaka 1207, Bangladesh.

Email: imranmahmud@daffodilvarsity.edu.bd

\section{INTRODUCTION}

In Bangladesh, the product business as of now utilizes more than 700.000 in more than 2.000 IT organizations. Another report recommended that there were 956 part IT organizations in the Bangladesh association of software and information services (BASIS), of which 382 asserted that a sum of $\$ 594.73$ million worth of IT and IT-empowered administrations (ITES) items were sent out. Once more, as per the Prime Minister's ICT undertakings guide, Mr. Sajib Wazed Joy, Bangladesh's fares from the ICT division are worth $\$ 700$ million [1].

In spite of making quick commitments to Bangladesh's economy, a significant issue has been watched decently habitually among data innovation (IT) experts in late year's viz. dismiss. Premise President Mustafa Jabbar declared that solitary 8 percent of around 10.000 alumni in software engineering and designing (CSE) in Bangladesh add to programming advancement. The product organizations of Bangladesh right now require critical quantities of IT professionals [1].

Dismiss implies the IT proficient deserts this region in order to possess a situation in an alternate territory, either in a similar organization or in another, occasionally expecting an administrative capacity, now and again traveling to another country for higher examinations, or going in for educating or preparing 
employments. With associations confronting difficulties in their endeavors to recruit extra staff, IT experts are being approached to do considerably more, frequently prompting burnout, dismiss, and dismiss expectations.

Prior, scientists from human asset and data framework disciplines focused on turnover goals, however as of late, analysts are starting to move their Turn away intention (TAI). As a fundamental report, we looked through the Google Scholar database, however neglected to distinguish any single research in Bangladesh that concentrated on dismiss expectations. In this way, the exploration announced here concentrated on the elements affecting TAI and, all the more critically, the effect of the danger of expert out of date quality. Our exploration question, in this way, is: "What are the variables that impact dismiss aims among programming experts? An extra commitment was made by estimating the impact of the risk of expert out of date quality on TAI."

\section{LITERATURE REVIEW}

\subsection{Turn-away intentions}

In [2] explained that investigations into workplace exhaustion may assist HR professionals in identifying the factors related to turn-away intentions. Many see it as the initial manifestation of the burnout process [3]. Again, [4] consider it more appropriate to view cynicism and curtailed personal accomplishment (the other two dimensions) as symptoms, and not as components that comprise burnout. As an exploratory study, one that is centered on mitigating TAI, we focus on the dimension of exhaustion.

IT studies have emphasized how exhaustion causes outcomes like turnover (e.g., [5, 6]). However, it is only recently that researchers have focused on TAI and its links with burnout related to the job [7]. In the literature on burnout, researchers have started to recognize the need to examine work-related experiences across an individual's career [8]. Nevertheless, the links between exhaustion caused by one's career and TAI have not been fully explored yet. This research aims to find out how an IT professional's workplace experiences may lead to exhaustion caused by IT career experience (i.e., the feeling that one is being overextended by one's IT work experience or IT career) and TAI. We adapt [5] turnover intention model to the context of an IT professional's career.

\subsection{IT career experience demands}

Perceived workload (PW) is often seen as predicting exhaustion caused by work, especially in the case of IT professionals [9] (Rigas 2009). PW is of particular interest in the context of ITCE. This is because the work practices in an IT work environment often entail long working hours, after-hour meetings, late nights, on-call duty, and of continually being in a state of rush or crisis .

Another stressor that can cause extreme exhaustion is work-family conflict (WFC) [5]. In their study, they look at individuals' time in their IT career to look at career-family conflict (CFC). The idea delineates the impact of the continued and oft-incompatible demands that career and family life place on IT employees. When we consider CFC, we recognize the identification mechanisms present here, since people define themselves by their different responsibilities in life. These include career, family, community, civic duties and so on [10]. But we deal only with career and family. An individual's career, we state, does have a certain degree of significance. It can constitute a major segment of his/her life responsibilities, depending on the situations. When one's career acquires further meaning, this significance is not specific to the job; it depends on the IT career experiences. In addition, many characteristics of the IT profession are seen negatively (such as on-call status). These intrinsic pressures can affect the balance between work/career and family [2]. Dovetailing with our interviews, a participant in the study by [11] asserted: "The pace [of IT] is very fast which can cause problems when trying to balance home and work life." These characteristics are found throughout the IT profession, and, so, we can state that the conflict between the demands imposed by one's home life and career can appear across individuals' ITCE and lead to exhaustion.

\subsection{IT career resources}

As a major resource in an employee's ITCE, fairness acquires significance in our context. If an IT employee believes that there is fairness in his/her promotions and job responsibilities over the duration of his/her career experience, then this criterion may be connected to the profession, not just a specific organizational context. [5] indicated the importance of looking beyond the job at the profession since it concerns the topic of fairness: "pay and reward equity was important to the RWs [road warriors] we interviewed, especially as they compared their job and career path to those at headquarters" (p. 3). In consonance with Ahuja et al., we anticipate that collective perceptions of fairness across an individual's ITCE may negatively impact EITCE. Previous qualitative studies have found that there are perceptions of inequities and the concept of fairness in the IT profession in connection with pay, promotion, and workload. In [12] found that fairness as regards pay was an important predictor of career satisfaction. In consonance 
with these studies, several people in our focus group interviews remarked on inequities across the IT field. They themselves acknowledged that there are inequities in pay and promotion. For example, one participant asserted that "pay/promotion inequities based on race/gender exist (although hard to separate)," while another stated that "there are definitely some [salary] inequities."

At the level of the job, [13] indicate that the impact of stress on a worker's health depends on the degree of control he/she is able to exert while carrying out his/her job duties (i.e., autonomy). While looking across one's ITCE, perceptions of control over an individual's career may increase the capacity to adapt one's behavior for responding to new challenges. This is because it gives individuals opportunities to select positions that enable them to develop their skills and abilities. "Career control reflects the extent to which individuals believe they can predict and influence the direction of their careers" [14]. A respondent in a previous research study shared, "I've reinvented my career four times at this company, without ever leaving IT and it's been a great opportunity that I don't see in other industries" [2]. Control over one's career also gives individuals opportunities to adjust their work in accordance with their needs, abilities, and situations. This might be particularly valid for professionals, who are often expected to invest most of their time and energy in work [15]. Individuals who feel they are in control of their careers can decide when and how to dedicate time to their careers. In addition, studies have detected a negative relationship between control and exhaustion at the level of the profession federal civil servants [14]; nurses. We propose that individuals in the IT profession who perceive they have higher levels of control over their careers will report lower levels of EITCE.

\subsection{Threat of professional obsolescence}

Nexpectedly, information technology professionals (ITPs)-individuals who actualize creative mechanical change the most-are enormously powerless themselves to the effect of such change. Such weakness is evident in the out of date quality of their expert abilities [16]. Such out of date quality demonstrates the rot or decrease in the estimation of expert abilities. It emerges when the officeholder's capacities, prior adequate for the prerequisites of the calling, presently don't coordinate the current work requests and expertise necessities because of changes in the information area. Against amassing after some time, ITP ability is ceaselessly disintegrated with the "capability annihilating" nature of IT. Subsequently, the dread of falling behind in the innovative race and the continuous strain to remain refreshed through progressing learning are extra stressors far beyond tight cutoff times and an intense outstanding task at hand [17]. Despite the fact that proficient outdated nature is viewed as a pivotal issue in IT examine, hardly any examinations have dissected such a risk and its outcomes. In any case, the rate of innovative change and out of date quality can significantly influence the representative mentally and physiologically. As indicated by [18], out of date quality isn't experienced consistently by all people. Since the effect of oldness has not been completely comprehended, tries to contemplate out of date quality in associations should investigate how it shifts among people.

\section{MODEL DEVELOPMENT}

We started from the research of [2], who utilized information system career-related demands and resources as predictors of TAI.

\subsection{IT career demands and exhaustion}

In [2] adopted the variables called work overload (WO) and career-family conflict (CFC) from the turnover model of [5]. According to [5] Ahuja et al., work overload is the perception that assigned work exceeds an individual's capability or skill level and work-home conflict is the perceived conflict between the demands of work and family. The research of [2] found a significant relationship between WO and CFC on workplace exhaustion (EX). Based on that evidence, our hypotheses are:

$\mathrm{H} 1$ : WO is positively associated with EX of IT professionals.

$\mathrm{H} 2$ : CFC is positively associated with EX of IT professionals.

\subsection{IT career resources and exhaustion}

The research of [2] also investigated the influence of IT career resources (fairness and control of career) on EX and obtained significant results. In [19] mentioned fairness (FRN) like pay scale, promotion, or other reward equity is a very important factor for IT professionals. Control over one's career (COC) also provides individuals with opportunities to adjust their work in accordance with their needs, abilities, and circumstances. Within the IS profession, we propose that higher levels of fairness and individuals' perceived control of their career leads to lower level of EX. Therefore, the hypotheses are:

H3: FRN is positively associated with EX of IT professionals.

$\mathrm{H} 4$ : COC is positively associated with EX of IT professionals. 


\subsection{IT career exhaustion and turn away intention}

Exhaustion (EX) has been found to be a significant correlate for TAI by [2]. If any IT professional perceives exhaustion, then the only solution may be to change professions or switching to another profession. To confirm these relationships within our context, we hypothesize:

H5: EX is positively associated with TAI of IT professionals.

\subsection{Threat of professional obsolescence and turn-away intentions}

Professional obsolescence is considered a crucial issue [20]. The nature of the information technology-related work and profession are rapidly changing. As a result, fear of falling behind in the technology race exerts pressure on professionals to keep themselves in line by learning new skills, which puts extra pressure. A significant negative relationship between TPO and career commitment [21] was identified. Failure to maintain and update one's skills can quickly make a professional obsolete. Therefore, we believe a higher level of TPO will lead to a higher level of TAI. Hence:

H6: TPO is positively associated with TAI of IT professionals.

Our model see Figure 1 illustrates the concepts of exhaustion, professional obsolescence, and turnover in the domain of an IT professional's career by presenting a set of representative antecedents adapted from [2, 21].

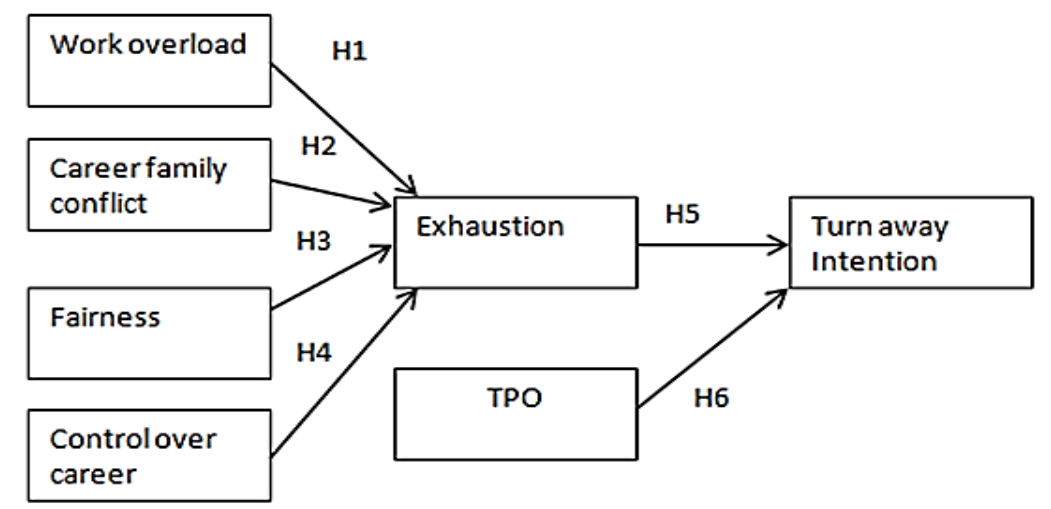

Figure 1. Proposed research model

\section{RESEARCH METHOD}

\subsection{Study design}

This exploration is a piece of a 6 months study. We reached a few programming firms in Dhaka, the capital of Bangladesh. This examination put forth a concentrated effort regulated survey in gathering the information. Members for the principle study were people working in those product firms. A sum of 300 surveys (printed) were circulated among the members. An aggregate of 185 polls were come back with a reaction pace of $61.6 \%$.

\subsection{Measures}

The poll comprises of two segments. The main area evoked the segment information; the subsequent segment was centered around things to gauge the builds of our exploration model. The survey things were adjusted from approved instruments. All things were estimated on a five-point Likert type scale. All things for WO, CFC, COC, FRN and EX were adjusted from the exploration of [2]. Things of TAI and TPO were adjusted from $[2,21]$ separately.

\subsection{Data analysis strategy}

As recommended by [22, 23], we originally tried the ordinariness of the information utilizing by surveying univariate and multivariate skewness and kurtosis utilizing the product accessible at: https://webpower.psychstat.org/models/kurtosis/results.php?url=fb9771ad65087c96bdc6a313929fa338. The outcomes demonstrated that the information passesd all the univariate ordinariness test as the estimation of skewness and kurtosis were inside the \pm 1 . Further to that the multivariate ordinariness which is generally by taking a gander at the Mardia's multivariate skewness $(\beta=6.283, p<0.01)$ and Mardia's multivariate kurtosis $(\beta=66.608, p<0.01)$, in this way we continued to utilize SmartPLS which is a non-parametric investigation programming. 
To examine the examination model we utilized the partial least squares (PLS) investigation utilizing the SmartPLS 3.0 programming [24, 25]. Following the suggested two-phase expository methodology, we tried the estimation model (legitimacy and unwavering quality of the measures) trailed by an assessment of the basic model ie; testing the theorized relationship [26, 27]. To test the importance of the way coefficients and the loadings a bootstrapping technique (5000 resamples) was utilized [28].

\subsection{Demographic information}

Table 1 shows that out of 185 people, 128 (69.19\%) were male and 57 (30.81\%) were female. As far as age extend, a large portion of the respondents (34.05\%) were matured between 25-30 years, $27.56 \%$ were between $25-30,24.32 \%$ were matured between $36-40$ and $26 \%$ were matured over 40 . An aggregate of $134(66.35 \%)$ were matured between 18-21 years and $63(29.03 \%)$ were between 22-25 years, while the remaining $10(4.6 \%)$ were over 25 years. With respect to, $167(76.95 \%)$ were male and $50(23.05 \%)$ were females. Then, $4.14 \%$ had understanding of perusing on the web papers for short of what one year, $53 \%$ had understanding of one to two years, $33.17 \%$ had understanding of three to four years, and $9.67 \%$ had understanding of over four years.

Table 1. Demographic information

\begin{tabular}{llll}
\hline & Category & Frequency & Percentage \\
\hline Gender & & & \\
& Male & 128 & 69.19 \\
Age Group & Female & 57 & 30.81 \\
& & & \\
& $25-30$ & 51 & 27.56 \\
& $31-35$ & 63 & 34.05 \\
& $36-40$ & 45 & 24.32 \\
& $40+$ & 26 & 14.05 \\
\hline
\end{tabular}

\section{RESULT AND FINDINGS}

\subsection{Measurement model}

In Table 2, average variance extracted (AVE) and composite reliability (CR) have been accounted for the estimation will be adequate if the AVE for each build is more noteworthy than 0.50 and CR is more noteworthy than $0.80[28,29]$. For this situation, all things are stacked exceptionally on their own inactive variable and hence all estimations have palatable degrees of dependability.

Table 2. Measurement model

\begin{tabular}{|c|c|c|c|c|}
\hline Construct & Item & Loadings & $\mathrm{CR}$ & AVE \\
\hline \multirow[t]{4}{*}{ Career Family Conflict } & $\mathrm{CFC1}$ & 0.610 & 0.825 & 0.544 \\
\hline & $\mathrm{CFC} 2$ & 0.754 & & \\
\hline & CFC3 & 0.806 & & \\
\hline & $\mathrm{CFC} 4$ & 0.764 & & \\
\hline \multirow[t]{4}{*}{ Control Over Career } & $\mathrm{COC} 2$ & 0.770 & 0.808 & 0.517 \\
\hline & $\mathrm{COC} 3$ & 0.833 & & \\
\hline & $\mathrm{COC} 4$ & 0.651 & & \\
\hline & COC6 & 0.599 & & \\
\hline \multirow[t]{4}{*}{ Workplace Exhaustion } & EX1 & 0.748 & 0.828 & 0.550 \\
\hline & EX2 & 0.766 & & \\
\hline & EX3 & 0.835 & & \\
\hline & EX4 & 0.598 & & \\
\hline \multirow[t]{3}{*}{ Fairness and Control of Career } & FRN2 & 0.860 & 0.772 & 0.536 \\
\hline & FRN3 & 0.726 & & \\
\hline & FRN5 & 0.585 & & \\
\hline \multirow[t]{4}{*}{ Tirn Away Intention } & TA1 & 0.597 & 0.809 & 0.517 \\
\hline & TA2 & 0.679 & & \\
\hline & TA3 & 0.822 & & \\
\hline & TA4 & 0.758 & & \\
\hline \multirow[t]{4}{*}{ Threat of Professional Obsolescence } & TPO1 & 0.627 & 0.799 & 0.501 \\
\hline & TPO3 & 0.796 & & \\
\hline & TPO4 & 0.769 & & \\
\hline & TPO5 & 0.622 & & \\
\hline \multirow[t]{3}{*}{ Work Overload } & WO1 & 0.782 & 0.756 & 0.511 \\
\hline & WO2 & 0.733 & & \\
\hline & WO4 & 0.619 & & \\
\hline
\end{tabular}


We tested the discriminant validity using the heterotrait-monotrait ratio of correlations. In [30] method and the results are shown in Table 3. If the HTMT value is greater than 1 [31] then there is a problem of discriminant validity. As all the values less than 1 as shown in Table 3 indicating that discriminant validity has been ascertained.

Table 3. Discriminant validity (HTMT ratio)

\begin{tabular}{lccccccc}
\hline & 1 & 2 & 3 & 4 & 5 & 6 & 7 \\
\hline 1. Career Family Conflict & & & & & & & \\
2. Control Over Career & 0.238 & & & & & & \\
3. Workplace Exhaustion & 0.586 & 0.224 & & & & & \\
4. Fairness and Control of Career & 0.295 & 0.223 & 0.249 & & & \\
5. Turn Away Intention & 0.578 & 0.197 & 0.689 & 0.381 & & \\
6. Threat of Professional Obsolescence & 0.570 & 0.263 & 0.406 & 0.391 & 0.742 & \\
7. Work Overload & 0.483 & 0.256 & 0.732 & 0.476 & 0.591 & 0.334 \\
\hline
\end{tabular}

\subsection{Structural model}

To test the hypotheses, the basic model was assessed. The model recommended that CFC, WO, FRN and COC clarifies 32.9\% fluctuation on EX. EX and our new factor TPO clarify $40.9 \%$ change on the trustworthy variable of TAI. If there should arise an occurrence of theory test result see Table 4, in number proof was discovered that speculation H1 (WO-> EX), H2 (CFC - > EX) and H4 (COC - > EX) were bolstered and was unequivocally huge with $\beta=0.369(\mathrm{p}<0.01), \beta=0.331(\mathrm{p}<0.01)$ and $\beta=-0.111$ $(\mathrm{p}<0.05)$ individually. The connection between assets which implies H3 (FRN-> EX) isn't huge. Moving further up to our model, as to IT experts dismiss goal, H5 (EX - > TAI) and H6 (TPO - > TAI) both are firmly noteworthy with $\beta=0.376(\mathrm{p}<0.01)$ and $\beta=0.420(\mathrm{p}<0.01)$. There were no issues of multicollinearity as the VIF esteems were all underneath 5 (Hair et al., 2017). The f2 values which gauges the substantive essentialness demonstrated that $\mathrm{H} 1, \mathrm{H} 5$ and $\mathrm{H} 5$ with medium impact and $\mathrm{H} 2$ and $\mathrm{H} 4$ with little impacts.

Table 4. Hypothesis testing result

\begin{tabular}{llllllllll}
\hline \multicolumn{1}{c}{ Hypothesis } & Std. Beta & Std. Error & t-value & p-value & $\mathrm{f}^{2}$ & VIF & LL & UL \\
\hline H1 & WO -> EX & 0.369 & 0.059 & 6.301 & $\mathrm{p}<.001$ & 0.174 & 1.166 & 0.287 & 0.474 \\
H2 & CFC -> EX & 0.331 & 0.062 & 5.346 & $\mathrm{p}<.001$ & 0.144 & 1.136 & 0.221 & 0.426 \\
H3 & FRN -> EX & 0.007 & 0.052 & 0.140 & 0.444 & 0.000 & 1.084 & 0.000 & 0.011 \\
H4 & COC -> EX & -0.111 & 0.058 & 1.906 & P $<0.05$ & 0.021 & 1.040 & -0.175 & -0.005 \\
H5 & EX -> TA & 0.376 & 0.057 & 6.622 & $\mathrm{p}<.001$ & 0.220 & 1.089 & 0.268 & 0.461 \\
H6 & TPO -> TA & 0.420 & 0.062 & 6.780 & $\mathrm{p}<.001$ & 0.274 & 1.089 & 0.321 & 0.525 \\
\hline
\end{tabular}

\section{DISCUSSION}

The examination objective of this examination was to explore the job of different components to gauge IT experts' dismiss goals. The exploration model we have created contended that separated from decency and command over profession, different factors are solid indicators for dismiss goals. The consequences of the current examination propose that the accompanying theories $\mathrm{H} 1, \mathrm{H} 2, \mathrm{H} 5$, and H6 are upheld. $\mathrm{H} 3$ and $\mathrm{H} 4$ are not bolstered.

On account of the connection between IT vocation requests, our theories $\mathrm{H} 1$ and $\mathrm{H} 2$ are bolstered. These outcomes are steady with the examination of [2]. Clearly IT experts require solid mental endeavors to live up to their outstanding task at hand desires. Inability to give that exertion implies the dismiss aim will be high. The board should prepare workers regarding compelling time the executives methodologies to manage these circumstances. As respects vocation family strife, our information proposes that CFC is a solid indicator. We recommend that to diminish the danger of work environment fatigue, associations ought to give important leave to the urban exercises of IT experts.

With respect to IT vocation assets, our speculations $\mathrm{H} 3$ and $\mathrm{H} 4$ were not noteworthy. These outcomes are not reliable with the aftereffects of [2]. Blended reactions were found about these two develops. We accept that reasonableness is available in the present IT showcase in Bangladesh. If there should arise an occurrence of COC, we expect that the ongoing expansion of outsourcing works lead the members to deal with their professions. Independent work has expanded in Bangladesh, which proposed that Bangladesh is positioned seventh among 186 nations where online occupations are redistributed.

Proof in regards to $\mathrm{H} 5$-which was the connection among EX and TAI-are reliable with the exploration of [2] and [5]. This may demonstrate that when an individual is depleted from an IT vocation, 
S/He may mull over withdrawal from the wellspring of the fatigue. Supervisors ought to distinguish and expel the potential factors that impact EX to decrease the TAI of qualified specialists.

Our last speculation-H6-infers the solid connection among TPO and TAI. A more significant level of TPO will prompt a more significant level of TAI. This outcome is predictable with the past aftereffect of [21]. Chiefs can give appropriate preparing to their IT experts to stay aware of the pace of progress in aptitudes and innovation.

Keeping up a certified and stable group of IT staff has been positioned one of the most basic elements for effective working of any association. We accept that our examination gives noteworthy hypothetical commitments by incorporating TPO with the model of [2]. This exploration gives a few viable ramifications to supervisors. In aggregate, we accept such a superior comprehension would help managers in arranging better techniques to increment good results.

\section{IMPLICATIONS}

There are two major contributions by this study to research as well as practice. Firstly, it extends a significant construct at the job level to the process of turnover among IT professionals, viz. work exhaustion, to their careers (EICTE). The study delineates the significance of EICTE by empirically testing the relationships between EICTE and TAI and a limited set of antecedents for EICTE. This study aims to innovatively explore the domains of EICTE and TAI, and intends to show that it is worth applying the idea of exhaustion at the job level to an IT professionals' career.

When we examine an IT professional's ITCE, a career perspective is necessary, one that considers the employee beyond his/her present situation. Since these factors are important for IT research related to jobs, research in future should examine how these factors can be applied and translated into experiences related to one's career. According to our study, fairness, as perceived, and its significance for individuals, surpass any specific job and spreads across the IT professional's ITCE. This finding is especially relevant since HR managers have their limitations-they can only control job and/or organizational factors. While general motors has employed an additional 1,500 IS professionals in 2013-2014 [32] and again 1,000 more IT professionals in 2014-2015 [33], perceptions need to be taken into account for those who have newly employed as well as the existing IT employees. Training programs within the firm should encourage and allow managers to more carefully prepare procedures and outcomes that are perceived as fair. Such an approach may result in benefits when a steady pool of potential qualified individuals is formed.

On the off chance that prizes are apportioned reasonably, they are probably going to be viable. It is the obligation of HR directors to ensure that ITPs see that they are reasonably compensated. They ought to view themselves as capable, significant, and commendable individuals from the firm. The administrators should make this an ordinary part of correspondence. Also, ITPs need to ceaselessly contribute their time, vitality, and other rare assets to refresh their insight and aptitudes to guarantee they don't linger behind innovative advances. Subsequently, supervisors should know how ITPs see the danger of outdated nature and what steps they should take to tackle the issue. IT firms should give ITPs chances to add to the targets of association while at the same time helping them meet their objectives in their separate vocations. Thus, it is essential to contribute assets to help dovetail hierarchical destinations and vocation prerequisites of people. Third, while selecting qualified applicants, proficient self-viability ought to be a rule for enrollment of ITPs. This is on the grounds that ITPs with a high level of fearlessness in the calling are probably going to act naturally persuaded. They will try to stay side by side of current turns of events and capable. In particular, proficient self-adequacy can alleviate the injurious impacts of the risk of expert oldness. With a high level of self-viability, the worker would have the option to support his/her expert vocation regardless of the approaching risk of expert outdated nature.

\section{CONCLUSION}

Overall, this study emphasizes that those in the IT profession should have realistic career previews. If one understands the peculiarities of the profession, one can potentially help curtail EITCE. Universities, professional associations, and organizations should talk to potential IT professionals in such a manner as to make it clear what the IT profession holds for them as far as resources (e.g., fairness) are concerned and what they can expect from it insofar as demands are concerned (e.g., workload).

\section{REFERENCES}

[1] The Daily Sun, "Only 8pc of CSE graduates contribute to software dev," 2017, [Online] Available: http://www.daily-sun.com/arcprint/details/207124/\%E2\%80\%98Only-8pc-of-CSE-graduates-contribute-tosoftwaredev\%E2\%80\%99-/2017-02-21. 
[2] Armstrong, D. J., Brooks, N. G., and Riemenschneider, C. K., "Exhaustion from information system career experience: Implications for turn-away intention,” Applied Psychology, vol. 86, no. 3, pp. 499-512, 2015.

[3] Schaufeli, W. B., Maslach, C., and Marek, T., "The future of burnout," Professional burnout: Recent developments in theory and research, pp. 253-259, 1993.

[4] Pawlowski, S. D., Kaganer, E. A., and Cater III, J. J., "Focusing the research agenda on burnout in IT: Social representations of burnout in the profession," European journal of information systems, vol. 16, no. 5, pp. 612-627, 2007.

[5] Ahuja, M. K., Chudoba, K. M., Kacmar, C. J., McKnight, D. H., and George, J. F., "IT road warriors: Balancing work-family conflict, job autonomy, and work overload to mitigate turnover intentions," Mis Quarterly, pp. 1-17, 2007.

[6] Rutner, P. S., Hardgrave, B. C., and McKnight, D. H., "Emotional dissonance and the information technology professional," Mis Quarterly, pp. 635-652, 2008.

[7] Shropshire, J., and Kadlec, C., "I'm leaving the IT field: The impact of stress, job insecurity, and burnout on IT professionals," International Journal of Information and Communication Technology Research, vol. 2, no. 1, 2012.

[8] Barbier, M., Hansez, I., Chmiel, N., and Demerouti, E., "Performance expectations, personal resources, and job resources: How do they predict work engagement?," European Journal of Work and Organizational Psychology, vol. 22, no. 6, pp. 750-762, 2013.

[9] Rigas, P. P., "A model of turnover intention among technically-oriented information systems professionals," Information Resources Management Journal, vol. 22, no. 1, pp. 1-23, 2009.

[10] Wolfram, H. J., and Gratton, L., "Gender role self-concept, categorical gender, and transactional-transformational leadership: Implications for perceived workgroup performance," Journal of Leadership \& Organizational Studies, vol. 21, no. 4, pp. 338-353, 2014.

[11] Riemenschneider, Cynthia K., et al., "Barriers facing women in the IT work force," ACM SIGMIS Database: The Database for Advances in Information Systems, vol. 37, no. 4, pp. 58-78, 2006.

[12] Clem, K. J., Promes, S. B., Glickman, S. W., Shah, A., Finkel, M. A., Pietrobon, R., and Cairns, C. B., "Factors enhancing career satisfaction among female emergency physicians," Annals of emergency medicine, vol. 51, no. 6, pp. 723-728, 2008.

[13] Amick III, B. C., and Östberg, O., "Office automation, occupational stress and health: A literature analysis with specific attention to expert systems," Office Technology and People, vol. 3, no. 3, pp. 191-209, 1987.

[14] Ito, J. K., and Brotheridge, C. M., "An examination of the roles of career uncertainty, flexibility, and control in predicting emotional exhaustion," Journal of Vocational Behavior, vol. 59, no. 3, pp. 406-424, 2001.

[15] Blair-Loy, M., and Jacobs, J. A., "Globalization, work hours, and the care deficit among stockbrokers," Gender \& Society, vol. 17, no. 2, pp. 230-249, 2003.

[16] Colomo-Palacios, R., Tovar-Caro, E., García-Crespo, Á., and Gómez-Berbís, J. M., "Identifying technical competences of IT Professionals: The case of software engineers," International Journal of Human Capital and Information Technology Professionals, vol. 1, no. 1, pp. 31-43, 2010.

[17] Mak, B. L., and Sockel, H., "A confirmatory factor analysis of IS employee motivation and retention," Information \& management, vol. 38 , no. 5, pp. 265-276, 2001.

[18] Pazy, A., "Cognitive schemata of professional obsolescence," Human Relations, vol. 47, no. 10, pp. 1167-1199, 1994.

[19] Allen, M. W., Reid, M., and Riemenschneider, C., "The role of laughter when discussing workplace barriers: Women in information technology jobs," Sex roles, vol. 50, no. 3-4, pp. 177-189, 2004.

[20] Ramos, E., and Joia, L. A., "An investigation into turn-away among information technology professionals in Brazil," The Journal of High Technology Management Research, vol. 24, no. 1, pp. 30-41, 2013.

[21] $\mathrm{Fu}$, J. R., and Chen, J. H., "Career commitment of information technology professionals: The investment model perspective," Information \& Management, vol. 52, no. 5, pp. 537-549, 2015.

[22] Hair, J. F., Ringle, C. M., and Sarstedt, M., "A primer on partial least squares structural equation modelling (PLS-SEM)," 2nd Ed. Thousand Oaks: Sage, 2017.

[23] Cain, M. K., Zhang, Z., and Yuan, K.-H., "Univariate and multivariate skewness and kurtosis for measuring nonnormality: Prevalence, influence and estimation," Behavior Research Methods, vol. 49, pp. 1716-1735, 2017.

[24] Ringle, C. M., Wende, S., and Becker, J. M., "SmartPLS 3. Boenningstedt: SmartPLS GmbH," 2015. [Online]. Available: http://www. smartpls.Com.

[25] Ramayah, T., Rahman, S. A., and Ling, N. C., "How do Consumption Values Influence Online Purchase Intention among School Leavers in Malaysia?," Revista Brasileira de Gestão de Negócios, vol. 20, no. 4, pp. 638-654, 2018.

[26] Mahmud, I., Ramayah, T., and Kurnia, S., "To use or not to use: Modelling end user grumbling as user resistance in pre-implementation stage of enterprise resource planning system," Information Systems, vol. 69, pp. 164-179, 2017.

[27] Alzahrani, A. I., Mahmud, I., Ramayah, T., Alfarraj, O., and Alalwan, N., "Extending the theory of planned behavior (TPB) to explain online game playing among Malaysian undergraduate students," Telematics and Informatics, vol. 34, no. 4, pp. 239-251, 2017.

[28] Hair, J. F., Risher, J. J., Sarstedt, M., and Ringle, C. M., "When to use and how to report the results of PLS-SEM," European Business Review, vol. 31, no. 1, pp. 2-24, 2019.

[29] Toma, T. R., Mahmud, I., Hossain, M. E., Jahan, N., Ramayah, T., and Jayapal, P., "To Read or Not to Read: Modeling Online Newspaper Reading Satisfaction and Its Impact on Revisit Intention and Word-Of-Mouth," Interdisciplinary Journal of Information, Knowledge, and Management, vol. 13, pp. 337-359, 2018.

[30] Henseler, J., Ringle, C. M., and Sarstedt, M., "A new criterion for assessing discriminant validity in variance-based structural equation modeling," Journal of the academy of marketing science, vol. 43, no. 1, pp. 115-135, 2015.

[31] Franke, G., and Sarstedt, M., "Heuristics versus statistics in discriminant validity testing: a comparison of four procedures," Internet Research, pp. 1-31, 2019. 
[32] Bomey, Nathan, "GM Wants to Hire 1,500 Tech Experts," USA Today, Oct. 2012. [Online]. Available: http://www.usatoday.com/story/money/business/2012/10/09/gm-recruiting-techexperts/1622371/.

[33] Rosenberg, D., "General motors opens fourth information technology center today," GM Authority, 2014. [Online]. Available: http://gmauthority.com/blog/2014/08/general-motors-opensfourth-information-technology-center-today/.

\section{BIOGRAPHIES OF AUTHORS}
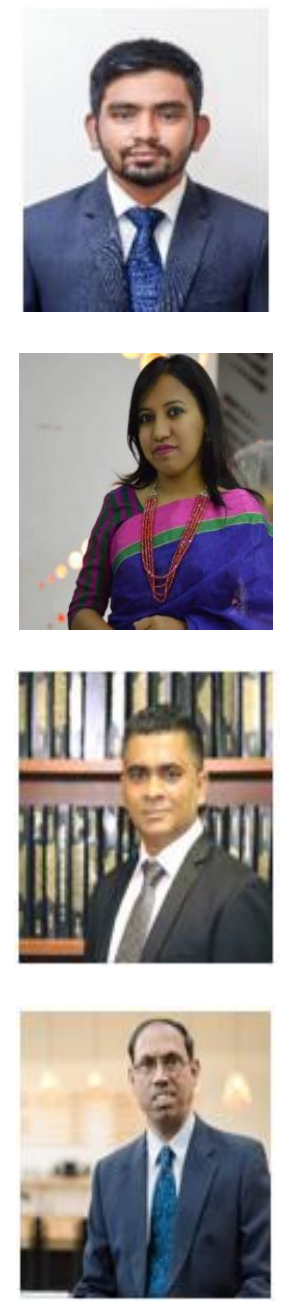

Md. Shohel Arman is a Lecturer and Alumni of Department of Software Engineering under Faculty of Science \& Information Technology in Daffodil International University, Dhaka, Bangladesh. He is an energetic and focused man since his student life. Currently he is focusing on his interested research area. His research interests are Machine learning, data mining, Internet of things (IOT), Cyber security and management information system (MIS).

Ms. Rozina Akter is an Assistant Professor and research coordinator at the Department of Business Administration in Daffodil International University, Bangladesh. She is an expert in the field of Banking and Insurance. Ms. Rozina has several publications in indexed journals. Her research interests are Banking, finance, insurance, economics, Banking model \& methods.

Dr. Imran Mahmud is the head of the department of Department of Information Technology and Management. Previously, he worked as a senior lecturer at Graduate School of Business in Universiti Sains Malaysia .He completed his PhD in technology management from Universiti Sains Malaysia. His research interests are human-computer interaction, usability testing, software engineering measurement/models and management information systems. Dr. Imran has several research papers on Enterprise Resource Planning and information system published in Sage and IEEE.

T. Ramayah, is currently a Professor of Technology Management, School of Management, Universiti Sains Malaysia, Visiting Professor King Saud University (Kingdom of Saudi Arabia), Minjiang University (China), Universiti Malaysia Sarawak (UNIMAS) and Adjunct Professor at Sunway University, Multimedia University (MMU) and Universiti Tenaga Nasional (UNITEN), Malaysia. 